\title{
Hyde's horrors
}

Can you tell a criminal from the look of his face? The "downright detestable" appearance of Robert Louis Stevenson's evil Mr Hyde stands in the same tradition as the images used by Darwin in his work on pathognomics.
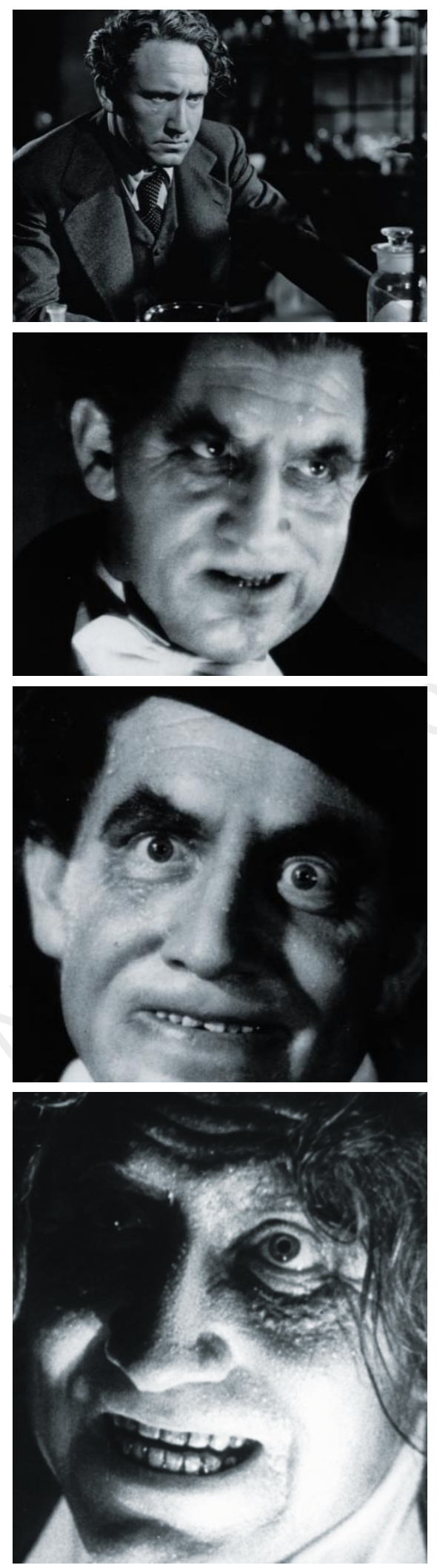

Spencer Tracy as Dr Jekyll and Mr Hyde from Victor Fleming's 1941 film.

\section{Martin Kemp}

1 ow the image of science and its practitioners enters public consciousness frequently in caricatured form - cannot be dismissed as irrelevant to its professional practice. Science institutions are as subject to political decision-taking in the context of public opinion as any other bodies funded from state and private purses. And even the grossest of visual distortions feed on images promulgated by scientists themselves. The 'horror' film is a case in point.

Robert Louis Stevenson, the Edinburgh engineer and qualified lawyer, wrote his classic The Strange Case of Dr Jekyll and Mr Hyde (1886) in the heyday of physiognomics, craniology and anthropometry, and in the wake of Francis Galton's new science of eugenics. These disciplines flourished in a scientific climate that was obsessed with the classification and definition of 'types' through precise characterization and minute measurement. In Stevenson's original text, it is striking how subtle and elusive were the visual signs of the degenerate and regressive Hyde released by Jekyll's chemical cocktail.

Mr Enfield, the first witness, typifies the problems: "He is not easy to describe. There is something wrong with his appearance; something displeasing, something downright detestable. I never saw a man so disliked, and yet I scarce know why. He must be deformed somewhere; he gives a strong feeling of deformity, although I couldn't specify the point.'

\section{A conviction that measurements of} extraordinary refinement - beyond simple descriptions - were needed to define 'types' through facial and cranial formations lay at the heart of several large-scale research enterprises in the nineteenth century.

These included the programme of craniometry undertaken by Paul Broca, founder of the Parisian Anthropological Society in 1859 , the photographic databanks of eugenic groups built up by Galton in the 1870s and 1880s, and Alphonse Bertillon's programme of criminological measurement undertaken for the Paris police towards the end of the century.

Inevitably, when "the animal within me licking the chops of memory" (in Jekyll's vivid evocation) came to be visualized in popular cinema, a more blatant characterization was required than that in the novel. The physiognomy provided by director Victor Fleming for Spencer Tracy in 1941 was not the most crudely bestial of the filmed Hydes, but his range of manic expressions stood in a long tradition of exaggerated pathognomics. The images used by Charles Darwin in his The Expression of the Emotions in Man and Animals (1872), including the remarkable photographs of Duchenne de Boulogne and drawings by leading illustrators, stand in this tradition.

Darwin set human expression in the broader context of evolution, not in terms of traditional parallels between human facial types and animal physiognomies but through an understanding of the origins of the expressive mechanisms.

He wrote: "As long as man and all other animals are viewed as independent creations, an effectual stop is put to our natural desire to investigate as far as possible the causes of expression.... With mankind some expressions, such as the bristling of the hair under the influence of extreme terror, or the uncovering of the teeth under that of furious rage, can hardly be understood except on the belief that man once existed in a much lower and animal-like condition.'

We still talk of those who perpetrate atrocities as 'animals' or 'beasts', and scrutinize the faces of criminals that stare out of newspaper photographs for signs of bestiality. And the Galton laboratory at University College London has a web site seeking physiognomic volunteers for its collaborative project on the genetics of human facial features, for which the Forensic Science Service is a funding agency.

Martin Kemp is in the Department of the History of Art, University of Oxford, 35 Beaumont Street, Oxford OX12PG, UK

e-mail:martin.kemp@trinity.oxford.ac.uk

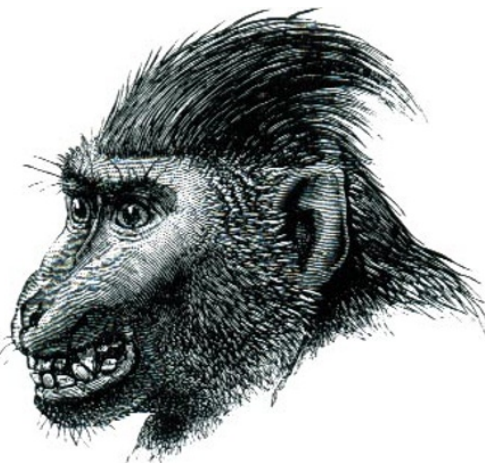

Fig. 17. The same, when pleased by bring caress?i. Joseph Wolf's Niger macaque (Cynopithecus niger) aroused by stroking, engraved in Charles Darwin's The Expression of the Emotions in Man and Animals (1872). 